\title{
Comparisons of the Clinicopathological Characteristics and the Expression of Tumor Biomarkers among Luminal, HER2-Enriched and Triple Negative Breast Cancer
}

Guangxu Liu ${ }^{1,2}$, Shengnan Ren ${ }^{3}$, Yuxiang Yan ${ }^{1,2}$, Jie Zhang ${ }^{1,2}$, Yanxia Luo ${ }^{1,2}$, Fen Liu ${ }^{1,2}$, Xiaoxia Peng ${ }^{1,2}$, Ling Zhang ${ }^{1,2}$, Xu Han ${ }^{1,2}$, Yuncui Yu ${ }^{1,2}$, Rong Zhu ${ }^{1,2}$, Ruiying Kang ${ }^{1,2}$, Jie $\mathrm{Li}^{1,2}$, Xuedong Fang ${ }^{3^{\star}}$ and Yan $\mathrm{He}^{1,2^{\star}}$

${ }^{1}$ Department of Epidemiology and Health Statistics, School of Public Health, Capital Medical University, Beijing, China

${ }^{2}$ Beijing Municipal Key Laboratory of Clinical Epidemiology, Beijing, China

${ }^{3}$ Department of General surgery, China-Japan Union Hospital of Jilin University, China

*Corresponding author: Yan He, Rm. 207, Jieping Building, Capital Medical University, Beijing, China 100069, Tel: (86) 010-83911779; Fax: (86) 010-83911779; Email: yanhe118@sina.com

Rec date: March 16, 2015 Acc date: April 13, 2015 Pub date: April 20, 2015

Copyright: @ 2015 Liu G, et al. This is an open-access article distributed under the terms of the Creative Commons Attribution License, which permits unrestricted use, distribution, and reproduction in any medium, provided the original author and source are credited.

\begin{abstract}
Objectives: The aim of this study was to compare the clinicopathological characteristics and the expression of tumor biomarkers among luminal breast cancer (LBC), HER2-enriched breast cancer (HEBC), and triple negative breast cancer (TNBC) in Chinese women.

Methods: According to the result of IHC staining detection, 683 breast cancer patients undergoing surgery from January 2009 to December 2010 were classified into three subtypes: LBC (ER+ and/or PR+, HER2-), HEBC (ER-, PR-, HER2+) and TNBC (ER-, PR-, HER2-).

Results: Significant difference in tumor grade, tumor size and TNM stage was observed both in $\mathrm{HEBC}$ $(P<0.0001, P=0.001$ and $P<0.0001$, respectively) and TNBC $(P<0.0001, P<0.0001$ and $P=0.009$, respectively $)$ when compared with LBC. The rate of lymph node metastasis in LBC was $14.4 \%$ and $18.1 \%$ lower respectively than that in HEBC $(P=0.001)$ and TNBC $(P=0.001)$. The Ki-67 expression in $L B C$ was $17.1 \%$ and $13.9 \%$ lower respectively than that in HEBC $(P<0.001)$ and TNBC $(P=0.016)$. Furthermore, the tumor grade II/III in TNBC was significantly higher than that in HEBC $(\mathrm{P}<0.001)$, and the expression of p53 and EGFR in TNBC was $15.0 \%$ and $29.9 \%$ higher than that in $\mathrm{HEBC}(\mathrm{P}=0.002, \mathrm{P}=0.011)$. Additionally, the higher tumor grade was a risk factor for the expression of p53 and EGFR in TNBC.
\end{abstract}

Conclusions: The distinct intrinsic BC subtypes exhibited the heterogeneity in clinicopathological characteristics and biomarkers expression. The individualized therapy of breast cancer should be more emphasized on the strategy of treatment.

Keywords: Breast cancer; Clinicopathological characteristics; Intrinsic subtype; Tumor biomarkers

\section{Introduction}

Breast cancer $(\mathrm{BC})$ is the most frequently diagnosed cancer and becomes the leading cause of cancer death in female worldwide [1]. In China, the crude incidence rate and mortality rate of female breast cancer during 2003-2007 were 41.64 and 9.63 per 100,000 respectively, which were ranked as the top and sixth respectively among female cancers [2] leading to a serious threat to women's physical and mental health. Currently, single factor assessment is difficult to make the most suitable strategy for $\mathrm{BC}$ treatment and prognosis, since $\mathrm{BC}$ is involved with numerous factors, such as genes and proteins. However, the classification of $\mathrm{BC}$ intrinsic subtype based on some biomarkers was suggested as a common method to provide prognostic and predictive information for specific therapies [3] which classified BC into luminal breast cancer (LBC), HER2-enriched breast cancer (HEBC) and triple negative breast cancer (TNBC).
Different intrinsic subtypes of $\mathrm{BC}$ had distinct biological behaviour, prognosis, survival rate and risk of death [3-5]. What's more, both of the HEBC and TNBC subtype had poor prognosis and survival outcome compared to LBC $[3,6,7]$.To our best knowledge, most of the previous studies mainly focused on comparing the different clinicopathological characteristics between the subtypes of LBC with HEBC or TNBC. However, the difference between subtypes of TNBC and HEBC was still poorly understood.

The TNBC and HEBC subtype accounted for $12.18 \%$ 26.0\% [8-11] and $17.4 \% \sim 30.0 \%[7,8,12]$ of Chinese BC patients respectively, so this study would provide useful information for the individual therapy for both of the TNBC and HEBC through analyzing the difference of their clinicopathological characteristics.

\section{Materials and Methods}

\section{Patients and clinicopathological parameters criteria}

We retrospectively collected clinical data of breast cancer (BC) patients at the 2nd affiliated hospital, Norman Bethune Medical 
Citation: Liu G, Ren S, Yan Y, Zhang J, Luo Y, et al. (2015) Comparisons of the Clinicopathological Characteristics and the Expression of Tumor Biomarkers among Luminal, HER2-Enriched and Triple Negative Breast Cancer. Gen Med (Los Angel) 3: 184. doi: $10.4172 / 2327-5146.1000184$

Page 2 of 6

Science of Jilin University from January 2009 to December 2010 Among the 698 female BC patients, 15 were excluded from analysis for part important baseline information missing $(n=12)$ and cancer tissues not available $(\mathrm{n}=3)$. As a result, $683 \mathrm{BC}$ patients were finally enrolled

The TNM stage was determined based on the American Joint Committee on Cancer (AJCC) criteria and the histological grade was assessed according to the modified Bloom-Richardson classification. The pathological types were assessed in accordance with the criterion of the world health organization (WHO) breast cancer pathology. Lymph node metastasis was defined as any metastasis in local region of ipsilateral axillary, supraclavicular, or internal mammary lymph nodes, or distant region of other contralateral axillary lymph nodes as well as supraclavicular lymph nodes.

\section{Immunohistochemical staining and judgments of results}

Immunohistochemical staining was performed using the streptavidin biotin method (SP method) [4]. Tumors with $1 \%$ or more positively nuclear-stained cells were considered positive for estrogen receptor (ER) and progesterone receptor (PR) expression [13] human epidermal growth factor receptor-2 (HER2) staining was scored by counting the number of cells positively stained on the membrane and expressed as a percentage of total tumor cells: 0 , no staining; $1+$, weak incomplete membranous staining in any proportion of tumor cells; $2+$, complete membranous staining, either non-uniform or weak in at least $10 \%$ of tumor cells; and $3+$, uniform intense membranous staining in $>25 \%$ of tumor cells. HER2 results were considered positive in cases with $3+$ membranous staining. EGFR and Bcl-2 stains were considered positive if any (weak or strong) cytoplasmic and/or membranous invasive carcinoma cell staining was observed. The diagnosis was made by two pathologists who specialized in breast pathology through assessed each archival hematoxylin and eosin (H\&E) stained slides.

\section{Definition/Classification of intrinsic subtypes}

Based on IHC finding of ER, PR and HER2 expression, the patients were divided into three subtypes with reference to the reporting by Cheang et al. [13] luminal breast cancer (ER+ and/or PR+, HER2-), HER2-enriched breast cancer (ER-, PR- and HER2+), and triplenegative subtype(ER-, PR- and HER2-).

\section{Statistical Analysis}

An independent t-test was used for the comparison of age between subtypes. The differences of clinicopathological characteristics in histological type, lymph node metastasis and the expression of biomarkers between the BC subtypes were evaluated by chi-square test. Fisher's exact test was used when appropriate.

The differences of the clinicopathological characteristics in tumor grade, ranked tumor size and TNM stage were evaluated by the rank sum test. An unconditional logistic regression was used to assess the association of some clinicopathological characteristics and the biomarkers expression in TNBC and HEBC, in which age was adjusted as a confounding factor. All statistical tests were two-sided, and Pvalues less than 0.05 were considered statistically significant. The statistical software SPSS version 19.0 (IBM Corp., Armonk, USA) was used for all statistical analyses.

\section{Results}

\section{General information and clinicopathological characteristics of the patients}

A total of 683 female breast cancer cases were enrolled, with a mean age of 51.6 \pm 10.8 years (range: $23-96$ years). According to the TNM classification developed by American Joint Committee on Cancer (AJCC), the majority of patients were diagnosed with stage II breast cancer $(n=319 ; 46.7 \%)$, nearly a quarter was with stage I $(n=167$; $24.5 \%)$, and the rest was with stage III ( $\mathrm{n}=197,28.8 \%)$.

Tumor size was available for 642 (93.4\%) samples, in which 293 (45.6\%) samples were less than $2 \mathrm{~cm}, 318$ (49.5\%) were within $2-5 \mathrm{~cm}$, and $31(4.9 \%)$ were more than $5 \mathrm{~cm}$. The pathology assessment indicated that 388 cases $(56.8 \%)$ had involved in lymph node metastasis. Among the patients, 338 (53.9\%) were in tumor grade II, $179(28.5 \%)$ in grade I and $111(17.6 \%)$ cases in grade III. Most of the tumors were invasive ductal carcinoma (82.1\%).

More than half of the samples were positive for ER $(n=485,71 \%)$ or $\operatorname{PR}(n=360,52.7 \%)$, however, the HER $2 /$ neu positive samples were only about a quarter $(n=188,27.6 \%)$. In this study, the highest frequency of intrinsic subtype defined by the expression of ER, PR and HER2/neu was luminal $(n=408,59.2 \%)$, followed by HER2-enriched $(\mathrm{n}=182,27.2 \%)$, and triple negative $(\mathrm{n}=93,13.6 \%)$. About $52.9 \%$ $(n=361)$ samples were positive for Ki-67 and $34.1 \%(n=233)$ for $p 53$ expression. For EGFR and Bcl-2, the expression rate were $30.6 \%$ $(\mathrm{n}=165)$ and $56.0 \%(\mathrm{n}=302)$ respectively.

\section{Comparisons of clinicopathological characteristics among the intrinsic subtypes}

We used the pairwise comparison to compare the difference in clinicopathological characteristics among the BC intrinsic subtypes. The results showed that $\mathrm{LBC}$ cases exhibited a significant difference in tumor grade when comparing with HEBC cases $(\mathrm{P}<0.001)$ and TNBC cases $(\mathrm{P}<0.001)$ respectively.

The proportion of tumor size within $2-5 \mathrm{~cm}$ were higher in HEBC $(58.3 \%, \mathrm{P}=0.001)$ and TNBC $(65.9 \%, \mathrm{P}<0.001)$ than that in $\mathrm{LBC}$. For the TNM stage, most LBC cases were at stage I (43.1\%), which was different from the HEBC cases $(57.0 \%$ cases at stage II, $\mathrm{P}<0.001)$ and TNBC cases (53.8\% at stage II, $\mathrm{P}=0.009)$. Moreover, the rate of lymph node metastasis in LBC cases was $14.4 \%(\mathrm{P}=0.001)$ and $18.1 \%$ lower $(\mathrm{P}=0.001)$ than that in HEBC cases and TNBC cases respectively.

Notably, we observed that the proportion of tumor with grade II/III in TNBC subtype was significantly higher than that in HEBC (tumor grade II $42.4 \%$ vs. 35.8 , tumor grade III $54.3 \%$ vs. $27.9 \%$; $\mathrm{P}<0.001$ ), which indicated that the different clinicopathological characteristics was existed even between the subtypes both with poor prognosis. No significant difference was found in other clinicopathological characteristics between the subtypes of TNBC and HEBC in this study.

\section{Comparisons of the expression of biomarkers among the intrinsic subtypes}

In this study, the positive expression of $\mathrm{Ki}-67$ in $\mathrm{LBC}$ was $17.1 \%$ and $13.9 \%$ lower than in HEBC $(\mathrm{P}<0.0001)$ and TNBC $(\mathrm{P}=0.015)$, respectively; whereas, the expression of $\mathrm{Bcl}-2$ in $\mathrm{LBC}$ subtype was 49.7\% $(\mathrm{P}<0.0001)$ and $45.9 \%(\mathrm{P}<0.0001)$ higher than that in HEBC and TNBC, respectively (Table 1$)$. 
Citation: Liu G, Ren S, Yan Y, Zhang J, Luo Y, et al. (2015) Comparisons of the Clinicopathological Characteristics and the Expression of Tumor Biomarkers among Luminal, HER2-Enriched and Triple Negative Breast Cancer. Gen Med (Los Angel) 3: 184. doi: $10.4172 / 2327-5146.1000184$

Page 3 of 6

\begin{tabular}{|c|c|c|c|c|c|c|c|c|c|c|c|c|}
\hline \multirow{2}{*}{$\begin{array}{l}\text { Clinicopathological } \\
\text { characteristics }\end{array}$} & \multirow{2}{*}{ LBC } & \multirow{2}{*}{ HEBC } & \multirow{2}{*}{ TNBC } & \multicolumn{3}{|c|}{ LBC vs. HEBC } & \multicolumn{3}{|c|}{ LBC vs. TNBC } & \multicolumn{3}{|c|}{ HEBC vs. TNBC } \\
\hline & & & & $P^{a}$ & $P^{\mathrm{b}}$ & OR $(95 \% \mathrm{Cl})$ & $P^{a}$ & $P^{b}$ & OR $(95 \% \mathrm{Cl})$ & $P^{a}$ & $P^{\mathrm{b}}$ & OR $(95 \% \mathrm{Cl})$ \\
\hline Age (yearM $\pm S$ ) & $\begin{array}{l}51.3 \\
10.7\end{array}$ & $\begin{array}{l}52.1 \\
11.7\end{array}$ & $\begin{array}{ll}52.9 & \pm \\
9.5 & \end{array}$ & 0.327 & & & 0.135 & & & 0.544 & & \\
\hline \multicolumn{13}{|l|}{ Tumor grade } \\
\hline I & $111(28.0)$ & $65(36.3)$ & $3(3.3)$ & $\begin{array}{l}<0.000 \\
1\end{array}$ & 0.016 & $\begin{array}{l}0.676(0.492 \\
-0.928)\end{array}$ & $\begin{array}{l}<0.000 \\
1\end{array}$ & $\begin{array}{l}<0.000 \\
1\end{array}$ & $\begin{array}{l}8.414(5.178 \\
-13.686)\end{array}$ & $\begin{array}{l}<0.000 \\
1\end{array}$ & $\begin{array}{l}<0.000 \\
1\end{array}$ & $\begin{array}{l}5.695(. \\
529-9.191)\end{array}$ \\
\hline II & $246(62.0)$ & $64(35.8)$ & $39(42.4)$ & & & & & & & & & \\
\hline III & $40(10.1)$ & $50(27.9)$ & $50(54.3)$ & & & & & & & & & \\
\hline NA & & 7 & 1 & & & & & & & & & \\
\hline \multicolumn{13}{|l|}{ Tumor size, cm } \\
\hline$<2$ & $201(53.5)$ & $67(38.3)$ & $25(27.5)$ & 0.0001 & 0.011 & $\begin{array}{l}1.493(1.097 \\
-2.032)\end{array}$ & $\begin{array}{l}<0.000 \\
1\end{array}$ & $\begin{array}{l}<0.000 \\
1\end{array}$ & $\begin{array}{l}2.139(1.457 \\
-3.141)\end{array}$ & 0.14 & 0.053 & $\begin{array}{l}1.594(0.994 \\
-2.558)\end{array}$ \\
\hline 02-May & $156(41.5)$ & $102(58.3)$ & $60(65.9)$ & & & & & & & & & \\
\hline$>5$ & $19(5.1)$ & $6(3.4)$ & $6(6.6)$ & & & & & & & & & \\
\hline NA & & 11 & 2 & & & & & & & & & \\
\hline \multicolumn{13}{|l|}{ Histological type } \\
\hline Ductal & $326(80.7)$ & $155(83.3)$ & $80(86.0)$ & 0.443 & 0.457 & $\begin{array}{l}0.840(0.531 \\
-1.329)\end{array}$ & 0.231 & 0.224 & $\begin{array}{l}0.673(0.356 \\
-1.273)\end{array}$ & 0.561 & 0.545 & $\begin{array}{l}0.804(0.398 \\
-1.626)\end{array}$ \\
\hline Others & $78(19.3)$ & $31(16.7)$ & $13(14.0)$ & & & & & & & & & \\
\hline \multicolumn{13}{|l|}{ TNM stage } \\
\hline । & $174(43.1)$ & $43(23.1)$ & $24(15.8)$ & $\begin{array}{l}<0.000 \\
1\end{array}$ & 0.002 & $\begin{array}{l}0.446(0.264 \\
-0.752)\end{array}$ & 0.009 & 0.034 & $\begin{array}{l}0.487(0.251 \\
-0.941)\end{array}$ & 0.856 & 0.808 & $\begin{array}{l}0.954(0.654 \\
-1.393)\end{array}$ \\
\hline II & $163(40.3)$ & $106(57.0)$ & $50(53.8)$ & & & & & & & & & \\
\hline III/IV & $67(16.6)$ & $37(19.9)$ & $19(20.4)$ & & & & & & & & & \\
\hline \multicolumn{13}{|c|}{ Lymph node metastasis } \\
\hline Yes & $148(36.7)$ & $95(51.1)$ & $51(54.8)$ & 0.001 & $\begin{array}{l}<0.000 \\
1\end{array}$ & $\begin{array}{l}0.555(0.390 \\
-0.790)\end{array}$ & 0.001 & 0.002 & $\begin{array}{l}0.478(0.303 \\
-0.754)\end{array}$ & 0.553 & 0.551 & $\begin{array}{l}1.165(0.705 \\
-1.923)\end{array}$ \\
\hline No & $255(63.3)$ & $91(48.9)$ & $42(45.2)$ & & & & & & & & & \\
\hline
\end{tabular}

Table 1: Comparison of clinicopathological characteristics among HEBC, TNBC and LBC. LBC: luminal breast cancer; HEBC: HER2-enriched breast cancer; TNBC: triple negative breast cancer; $\mathrm{P}^{\mathrm{a}}$ : from univariate analysis; $\mathrm{P}^{\mathrm{b}}$ : from unconditional Logistic regression adjusted for age; $\mathrm{CI}$ : confidence interval; OR: odds ratio; NA: not available

By further comparing the expression of biomarkers between TNBC and HEBC, we found the positive expression of p53 and EGFR in TNBC was $15.0 \%(\mathrm{P}=0.015)$ and $29.9 \%(\mathrm{P}=0.016)$ higher than that in HEBC subtype (Table 2). Since less study was concerned about the different expression of biomarker between TNBC and HEBC, and also its associated factors, so we further investigated the factors associated with this difference.

Through the univariate analysis of the association between the clinicopathological characteristics and biomarkers expression, the results demonstrated that only the tumor grade was associated with the p53 $(\mathrm{P}<0.0001)$ and EGFR positive expression $(\mathrm{P}=0.036)$. The expression of $\mathrm{P} 53$ and EGFR was not correlated with tumor size $(\mathrm{P}=0.144, \mathrm{P}=0.796)$, TNM stage $(\mathrm{P}=0.822, \mathrm{P}=0.818)$ and lymph node metastasis $(\mathrm{P}=0.143, \mathrm{P}=0.674)$. After adjusting for age, the higher tumor grade was still a risk factor for the p53 $(\mathrm{P}<0.0001, \mathrm{OR}=2.187$, $95 \% \mathrm{CI}=1.237-3.868)$ and EGFR positive expression $(\mathrm{P}=0.007$, $\mathrm{OR}=0.879,95 \% \mathrm{CI}=0.470-1.642$ ) (Table 3 ). 
Citation: Liu G, Ren S, Yan Y, Zhang J, Luo Y, et al. (2015) Comparisons of the Clinicopathological Characteristics and the Expression of Tumor Biomarkers among Luminal, HER2-Enriched and Triple Negative Breast Cancer. Gen Med (Los Angel) 3: 184. doi: $10.4172 / 2327-5146.1000184$

Page 4 of 6

\begin{tabular}{|c|c|c|c|c|c|c|c|c|c|c|c|c|}
\hline \multirow{2}{*}{$\begin{array}{l}\text { Tumor } \\
\text { biomarkers }\end{array}$} & \multirow{2}{*}{ LBC } & \multirow{2}{*}{ HEBC } & \multirow{2}{*}{ TNBC } & \multicolumn{3}{|c|}{ LBC vs. HEBC } & \multicolumn{3}{|c|}{ LBC vs. TNBC } & \multicolumn{3}{|c|}{ HEBC vs. TNBC } \\
\hline & & & & $P^{a}$ & $P^{\mathrm{b}}$ & OR (95\%Cl) & $P^{a}$ & $P^{\mathrm{b}}$ & OR (95\%Cl) & $P^{a}$ & $P^{b}$ & OR (95\%Cl) \\
\hline \multicolumn{13}{|l|}{ Ki-67 status } \\
\hline+ & $187(46.3)$ & 118(63.4) & $56(60.2)$ & $<0.0001$ & $<0.001$ & $\begin{array}{l}2.019(1.412-2 . \\
886)\end{array}$ & 0.015 & 0.016 & $\begin{array}{l}1.760(1.112-2 . \\
786)\end{array}$ & 0.6 & 0.679 & $\begin{array}{l}0.897(0.536-1 . \\
500)\end{array}$ \\
\hline- & $217(53.7)$ & $68(36.6)$ & $37(39.8)$ & & & & & & & & & \\
\hline \multicolumn{13}{|l|}{$\boldsymbol{p}^{53}$ status } \\
\hline+ & $105(26.0)$ & $98(52.7)$ & $63(67.7)$ & $<0.0001$ & $<0.001$ & $\begin{array}{l}3.155(2.192-4 . \\
541)\end{array}$ & 0.22 & 0.233 & $\begin{array}{l}1.347(0.826-2 . \\
197)\end{array}$ & 0.001 & 0.002 & $\begin{array}{l}0.438(0.260-0 . \\
740)\end{array}$ \\
\hline - & $299(74.0)$ & $88(47.3)$ & $30(32.3)$ & & & & & & & & & \\
\hline \multicolumn{13}{|l|}{ EGFR status } \\
\hline+ & $103(28.1)$ & $22(26.8)$ & $53(56.7)$ & 0.821 & 0.883 & $\begin{array}{l}0.960(0.559-1 . \\
649)\end{array}$ & 0.003 & 0.003 & $\begin{array}{l}2.047(1.274-3 . \\
289)\end{array}$ & 0.016 & 0.011 & $\begin{array}{l}2.339(1.215-4 . \\
503)\end{array}$ \\
\hline- & $264(71.9)$ & $60(73.2)$ & $40(43.3)$ & & & & & & & & & \\
\hline \multicolumn{13}{|l|}{ Bcl-2 status } \\
\hline+ & $263(71.7)$ & $18(22.0)$ & $24(25.8)$ & $<0.0001$ & $<0.001$ & $\begin{array}{l}0.112(0.063-0 . \\
199)\end{array}$ & $<0.0001$ & $<0.0001$ & $\begin{array}{l}0.120(0.070-0 . \\
206)\end{array}$ & 0.829 & 0.939 & $\begin{array}{l}1.029(0.500-2 . \\
117)\end{array}$ \\
\hline - & $104(28.3)$ & $64(78.0)$ & $69(74.2)$ & & & & & & & & & \\
\hline
\end{tabular}

Table 2: Comparison of the expression of biomarkers among HEBC, TNBC and LBC. LBC: luminal breast cancer; HEBC: HER2-enriched breast cancer; TNBC: triple negative breast cancer; EGFR: epidermal growth factor receptor; Bcl-2: B-cell lymphoma-2; $P^{a}$ : from univariate analysis; $P^{b}$ : from unconditional Logistic regression adjusted for age; CI: confidence interval; OR: odds ratio

\begin{tabular}{|c|c|c|c|c|c|c|c|c|c|c|}
\hline \multirow{2}{*}{$\begin{array}{l}\text { Clinicopathological } \\
\text { characteristics }\end{array}$} & \multicolumn{2}{|c|}{$p^{53}$} & \multirow[t]{2}{*}{$P^{a}$} & \multirow[t]{2}{*}{$P^{b}$} & \multirow[t]{2}{*}{ OR $(95 \% \mathrm{Cl})$} & \multicolumn{2}{|c|}{ EGFR } & \multirow[t]{2}{*}{$P^{a}$} & \multirow[t]{2}{*}{$P^{b}$} & \multirow[t]{2}{*}{ OR $(95 \% \mathrm{Cl})$} \\
\hline & + & - & & & & + & - & & & \\
\hline \multicolumn{11}{|l|}{ Tumor grade } \\
\hline 1 & $23(17.6)$ & $45(45.5)$ & $<0.0001$ & $<0.0001$ & $\begin{array}{l}2.308(1.598-3.3 \\
34)\end{array}$ & $1(1.5)$ & $7(6.7)$ & 0.036 & 0.007 & $\begin{array}{l}2.187(1.237-3.8 \\
68)\end{array}$ \\
\hline II & $57(43.5)$ & $35(35.4)$ & & & & $30(46.2)$ & $62(59.0)$ & & & \\
\hline III & $51(38.9)$ & $19(19.2)$ & & & & $34(52.3)$ & $36(34.3)$ & & & \\
\hline \multicolumn{11}{|l|}{ Tumor size } \\
\hline$<2 \mathrm{~cm}$ & $45(35.4)$ & $37(39.4)$ & 0.144 & 0.238 & $\begin{array}{l}1.344(0.823-2.1 \\
95)\end{array}$ & $26(41.3)$ & $44(43.6)$ & 0.796 & 0.961 & $\begin{array}{l}1.014(0.580-1.7 \\
72)\end{array}$ \\
\hline $2-5 \mathrm{~cm}$ & $74(58.3)$ & $56(59.6)$ & & & & $35(55.6)$ & $52(51.5)$ & & & \\
\hline$>5 \mathrm{~cm}$ & $8(6.3)$ & $1(1.1)$ & & & & $2(3.2)$ & $5(5.0)$ & & & \\
\hline \multicolumn{11}{|l|}{ TNM stage } \\
\hline I & $35(26.7)$ & $24(24.2)$ & 0.822 & 0.927 & $\begin{array}{l}0.982(0.663-1.4 \\
54)\end{array}$ & $16(24.6)$ & $31(29.5)$ & 0.639 & 0.818 & $\begin{array}{l}1.054(0.670-1.6 \\
59)\end{array}$ \\
\hline II & $70(53.4)$ & $57(57.6)$ & & & & $37(56.9)$ & $52(49.5)$ & & & \\
\hline III & $26(19.8)$ & $18(18.2)$ & & & & $12(18.5)$ & $22(21.0)$ & & & \\
\hline
\end{tabular}


Citation: Liu G, Ren S, Yan Y, Zhang J, Luo Y, et al. (2015) Comparisons of the Clinicopathological Characteristics and the Expression of Tumor Biomarkers among Luminal, HER2-Enriched and Triple Negative Breast Cancer. Gen Med (Los Angel) 3: 184. doi: $10.4172 / 2327-5146.1000184$

Page 5 of 6

\begin{tabular}{|l|l|l|l|l|l|l|l|l|l|l|}
\hline Yes & $64(48.9)$ & $58(58.6)$ & 0.143 & 0.14 & $\begin{array}{l}0.672(0.396-1.1 \\
39)\end{array}$ & $35(53.8)$ & $45(42.9)$ & 0.674 & 0.686 & $\begin{array}{l}0.879(0.470-1.6 \\
42)\end{array}$ \\
\hline No & $67(51.1)$ & $41(41.4)$ & & & & $30(46.2)$ & $60(57.1)$ & & & \\
\hline
\end{tabular}

Table 3: The association between tumor grade and biomarkers expression in HEBC and TNBC. HEBC: HER2-enriched breast cancer; TNBC: triple negative breast cancer; EGFR: epidermal growth factor receptor $P^{\mathrm{a}}$ : from univariate analysis. $P^{\mathrm{b}}$ : from unconditional Logistic regression adjusted for age. CI: confidence interval; OR: odds ratio

\section{Discussion}

In this study, we found that both of HEBC and TNBC subtypes showed more aggressive clinicopathological characteristics than that of LBC subtype, moreover, a difference in the clinicopathological characteristics between the subtypes of HEBC and TNBC was observed, indicating that difference treatment strategy was needed for the distinct subtype of $\mathrm{BC}$, even between the two subtypes of HEBC and TNBC both with poor prognosis.

This study showed that the TNBC and HEBC subtypes had larger tumor size, more advanced tumor grade and TNM stage. The higher positive rate in lymph node metastasis was also observed when compared with LBC subtype, which was consistent with previous studies [14-16]. Therefore the HEBC and TNBC were more malignant and aggressive compared with LBC. We found that the expression of $\mathrm{Ki}-67$ in HEBC and TNBC cases were significantly higher than that in LBC cases, which was consistent with the results from a meta-analysis [6]. We also demonstrated that the expression rate of p53 in HEBC and TNBC was higher than that in LBC. The positive rate of EGFR expression in TNBC was the highest (56.7\%) among three subtypes, which was similar with the previous report that $50-70 \%$ of TNBC cases expressed EGFR [17]. The Ki-67 is a nuclear antigen related to cell proliferation and also used as an IHC index for cell proliferative activity detection; [18] meanwhile, the p53 was reported to induce cell transformation and cancerization; [19] EGFR is a member of the tyrosine kinase receptor family and related to cell growth, proliferation and differentiation [17]. Thus, the higher expression of Ki-67, p53 and EGFR in subtypes of HEBC and TNBC might account for their more aggressive clinicopathological characteristics. Thus, our study indicated that the biomarkers related to cell proliferation and transformation may be served as the potential therapeutic targets for HEBC and TNBC patients. In this study, as high as $71.7 \%$ LBC expressed Bcl-2, which was consistent with the finding from Olivera et al., whereas the expression of this biomarker was only $22 \%$ and $26 \%$ respectively in HEBC and TNBC [20]. The Bcl-2 overexpression was associated with a favorable outcome [21] and the reduction in expression of $\mathrm{Bcl}-2$ protein was associated with progression and aggressive form of disease [22]. Our data also confirm the finding that the expression of $\mathrm{Bcl}-2$ was associated with less aggressive $\mathrm{BC}$ subtype.

In the present study, a higher tumor grade in TNBC subtype was observed compared with HEBC subtype, which was consistent with the some previous studies [23-25]. The high tumor grade indicated the lower differentiation degree of tumor cell, implying the tumor having more aggressive in the tumor progression and unfavourable outcome in the prognosis. Our results demonstrated that the tumor grade is a risk factor for p53 and EGFR expression in TNBC and HEBC, which may partly explain why p53 and EGFR is higher expressed in the TNBC than HEBC.
The limitation of this study was the relatively small sample size of TNBC cases, resulting in the inadequate representation of TNBC breast cancer patients. Despite the limitation, our findings are still of importance for breast cancer patients to perform individualized therapy. Considering the different expression of biomarkers like p53 and EGFR, which closely related to tumor cell proliferation, we believe the finding could contribute to a better understanding of tumor biology for those two breast cancer subtypes both with poor prognosis.

In conclusion, this study demonstrated the intrinsic BC subtypes exhibited the heterogeneity in clinicopathological characteristics and the biomarker expression. Therefore, the individualized strategy of therapy for different subtype of breast cancer should be more emphasized, even between HEBC and TNBC subtype

\section{Acknowledgments}

This work was supported by grants of key projects in the National Science \& Technology Pillar Program (No. SQ2015BA1300692) and Natural Science Foundation of Beijing Municipality to Yan $\mathrm{He}$ (7132027).

\section{References}

1. Balslev I, Axelsson CK, Zedeler K, Rasmussen BB, Carstensen B, et al. (1994) The Nottingham prognostic index applied to 9,149 patients from the studies of the Danish Breast Cancer Cooperative Group (DBCG). Breast cancer research and treatment 32: 281-290.

2. Huang Z, Chen W, Wu C, Zheng R, Chen J (2012) Incidence and mortality of female breast cancer in China-a report from 32 Chinese cancer registries, 2003-2007. Tumor 32: 435-439.

3. DiGiovanna MP, Stern DF, Edgerton SM, Whalen SG, Moore D, et al. (2005) Relationship of epidermal growth factor receptor expression to ErbB-2 signaling activity and prognosis in breast cancer patients. Journal of clinical oncology 23: 1152-1160.

4. Park S, Koo JS, Kim MS, Park HS, Lee JS, et al. (2012) Characteristics and outcomes according to molecular subtypes of breast cancer as classified by a panel of four biomarkers using immunohistochemistry. The Breast 21: 50-57.

5. Wolff AC, Hammond MEH, Schwartz JN, Hagerty KL, Allred DC, et al. (2006) American Society of Clinical Oncology/College of American Pathologists guideline recommendations for human epidermal growth factor receptor 2 testing in breast cancer. Journal of Clinical Oncology 25: 118-145.

6. de Azambuja E, Cardoso F, de Castro G, Colozza M, Mano MS, et al. (2007) Ki-67 as prognostic marker in early breast cancer: a meta-analysis of published studies involving 12155 patients. British journal of cancer 96: 1504-1513.

7. Ge QD, Lv N, Kong YN, Xie XH, He N, et al. (2012) Clinical characteristics and survival analysis of breast cancer molecular subtypes with hepatic metastases. Asian Pacific Journal of Cancer Prevention 13: 5081-5086. 
Citation: Liu G, Ren S, Yan Y, Zhang J, Luo Y, et al. (2015) Comparisons of the Clinicopathological Characteristics and the Expression of Tumor Biomarkers among Luminal, HER2-Enriched and Triple Negative Breast Cancer. Gen Med (Los Angel) 3: 184. doi: $10.4172 / 2327-5146.1000184$

Page 6 of 6

8. Huang CC, Tu SH, Lien HH, Jeng JY, Liu JS, et al.(2012) Prediction consistency and clinical presentations of breast cancer molecular subtypes for Han Chinese population. J Transl Med 10: S10.

9. Yin WJ, Lu JS, Di GH, Lin YP, Zhou LH, et al. (2009) Clinicopathological features of the triple-negative tumors in Chinese breast cancer patients. Breast cancer research and treatment 115: 325-333.

10. Yuan N, Meng M, Liu C, Feng L, Hou L, et al. (2014) Clinical characteristics and prognostic analysis of triplenegative breast cancer patients. Molecular and Clinical Oncology 2: 245-251.

11. Zhou L, Li K, Luo Y, Tian L, Wang M, et al. (2013) Novel prognostic markers for patients with triple-negative breast cancer. Human pathology 44: $2180-2187$.

12. Wu S-G, He Z-Y, Li Q, Li F-Y, Lin Q, et al. (2012) Predictive value of breast cancer molecular subtypes in Chinese patients with four or more positive nodes after postmastectomy radiotherapy. The Breast 21: 657-661.

13. Cheang MC, Chia SK, Voduc D, Gao D, Leung S, et al. (2009) Ki67 index HER2 status, and prognosis of patients with luminal B breast cancer. Journal of the National Cancer Institute.

14. Kim MJ, Ro JY, Ahn SH, Kim HH, Kim SB, et al. (2006) Clinicopathologic significance of the basal-like subtype of breast cancer: a comparison with hormone receptor and Her2/neu-overexpressing phenotypes. Human pathology 37: 1217-1226.

15. Nielsen TO, Hsu FD, Jensen K, Cheang M, Karaca G, et al. (2004) Immunohistochemical and clinical characterization of the basal-like subtype of invasive breast carcinoma. Clinical Cancer Research 10:5367-5374

16. Zaha DC, Lazar E, Lazureanu C (2010) Clinicopathologic features and five years survival analysis in molecular subtypes of breast cancer. Rom J Morphol Embryol 51: 85-89.
17. Burness ML, Grushko TA, Olopade OI (2010) Epidermal growth factor receptor in triple-negative and basal-like breast cancer: promising clinical target or only a marker? The Cancer Journal 16: 23-32.

18. Urruticoechea A, Smith IE, Dowsett M (2005) Proliferation marker Ki-67 in early breast cancer. Journal of clinical oncology 23: 7212-7220.

19. Kazemi M, Salehi Z, Chakosari RJ (2009) TP53 codon 72 polymorphism and breast cancer in northern Iran. Oncology Research Featuring Preclinical and Clinical Cancer Therapeutics 18: 25-30.

20. Mitrović O, Čokić V, Đikić D, Budeč M, Vignjević S, et al. (2013) Correlation between ER, PR, HER-2, Bcl-2, p53, proliferative and apoptotic indexes with HER-2 gene amplification and TOP2A gene amplification and deletion in four molecular subtypes of breast cancer. Targeted oncology:1-13.

21. Krajewski S, Krajewska M, Turner B, Pratt C, Howard B, et al. (1999) Prognostic significance of apoptosis regulators in breast cancer. Endocrine-Related Cancer 6: 29-40.

22. Daidone M, Luisi A, Veneroni S, Benini E, Silvestrini R (1999) Clinical studies of Bcl-2 and treatment benefit in breast cancer patients. Endocrine-related cancer 6: 61-68.

23. Onitilo AA, Engel JM, Greenlee RT, Mukesh BN (2009) Breast cancer subtypes based on ER/PR and Her2 expression: comparison of clinicopathologic features and survival. Clinical medicine \& research 7: 4-13.

24. Yamamoto Y, Iwase H (2010) Clinicopathological features and treatment strategy for triple-negative breast cancer. International journal of clinical oncology 15: 341-351.

25. Zhao J, Liu H, Wang M, Gu L, Guo X (2009) Characteristics and prognosis for molecular breast cancer subtypes in Chinese women. Journal of surgical oncology 100: 89-94. 